\title{
The Effect of Social Networks on the Quality of Political Thinking
}

\author{
Elif Erisen \\ California Polytechnic State University and Bilkent University \\ Cengiz Erisen \\ TOBB University of Economics and Technology
}

\begin{abstract}
In this article we investigate the effect of social networks on the quality of political thinking. First, the article introduces new social network concepts into the literature and develops the corresponding measures. Second, the article explores the quality of political thinking as a concept and develops its measures based on the volume and the causality of thoughts, and their integrative complexity. We make use of a survey to collect information on social networks and the experimental manipulation controls for the effect of policy frames. Our findings consistently show the significant negative impact of cohesive social networks on the quality of policy-relevant thinking. We conclude that close-knit social networks could create "social bubbles" that would limit how one communicates with others and reasons about politics.
\end{abstract}

KEY WORDS: social networks, political thinking, political discussion

\section{Introduction}

Social network effects reach all facets of life (Christakis \& Fowler, 2009), and, as Barabasi (2010) points out, they make most features of our lives highly predictable. ${ }^{1}$ Our political self is no exception, and the social networks literature in political science has addressed the effects of being embedded in a social network on various individual-level attitudinal and behavioral traits. One important individual characteristic, however, has been left largely unaddressed: how one thinks about politics.

We know that our social networks affect what we think. Regardless of the voters' largely documented lack of political information, their cognitive limitations, and irrationality (Campbell, Converse, Miller, \& Stokes, 1960; Kahneman \& Tversky, 1981; Lodge \& Taber, 2000; Simon, 1957; Taber \& Lodge, 2006), they have been shown to share what little information they have (see Berelson, Lazarfeld, \& McPhee, 1954 for an early study). In fact, social network analysis has been considered most valuable when information flow is central to the problem, such as the diffusion of policy-relevant information dependent on the network structure (Granovetter, 1973).

The literature's in-depth coverage of information flow via network ties, however, is nowhere to be found when it comes to network-based explanations of the thought processes that start once

\footnotetext{
${ }^{1}$ Network analysis is an emerging discipline including a variety of scholars from physicists to mathematicians to statisticians to social scientists (see Lazer et al., 2009).
} 
political information reaches the individual. This is the case despite the fact that several strands of research in political psychology have implications for network explanations of political thought processes. For instance, work on motivated reasoning might shed light on attitude congruency within a network (Kunda, 1987, 1990; Redlawsk, 2002; Taber \& Lodge, 2006) and link how we reason to network-level characteristics. More specifically regarding social networks, Granovetter (1983), building on earlier work by Coser (1975), links the network characteristic of having ties from multiple social contexts to cognitive flexibility. However, this assumption has not been empirically tested; neither could it produce more research linking networks to how we think about politics.

This article takes a novel step toward understanding the network effects on how we think by focusing on the link between the ego's own perception of her social network and her reasoning process. Political thinking is ever present, whether it is instigated in a low-information setting (Popkin, 1991) or jump-started by heuristics that handle the continuous flow of information (Lau \& Redlawsk, 2001). The reasoning process can be multifaceted and causal, or quite simple (Tetlock, 1985). In this article, we directly address the effects of social network characteristics on the extent to which political thinking about alternative policies that address the energy needs of the United States is rich and causal. We chose energy as the policy domain because of its salience and the public's familiarity with the issue.

In order to investigate social network effects on political thinking, we build new network concepts and the corresponding measures based on complete network data generated by a survey embedded in an experiment. Each network concept stands for a particular aspect of the network that corresponds to a unique characteristic of the information flow from the network. We translated the concepts into new measures that reflect the ego's perception of her social network. We collected data on political discussion networks by survey items and made use of a thought-listing procedure to gather the respondents' policy-relevant thoughts. We also controlled for affective cues by news frames. The experimental manipulation made sure that the findings are not artifacts of the news frames.

The findings show that social networks perceived by the ego as dominated by strong ties significantly worsen her reasoning about policies that are in line or against her prior attitudes on the issue. A cohesive network is associated with less thinking, and less causal and complex thinking on energy policies. Several other network characteristics, such as sharing similar political viewpoints, that have been shown to affect political attitudes or behavior are not related to the quality of the ego's reasoning on energy policies.

In the following sections, we first discuss the relevant social networks literature and introduce the social network concepts and explain what we mean by "quality of political thinking." Next, we lay out our expectations about social network effects on the quality of thinking and explain the research design and the key measures. Consequently, we present our findings, primarily the finding on the negative effect of cohesive networks on political thinking and reasoning. Last, we discuss our findings and the implications for future research.

\section{Social Network Characteristics}

We traced the network influence on political thinking in the literature in those social network studies that have implications for cognitive flexibility and the processing of social stimuli. The prime example is Granovetter's (1973) classic work on the "strength of weak ties," which shows that weak ties that bridge more people who otherwise have very little opportunity to contact each other are advantageous in terms of the individual's exposure to new information, experiences, or opportunities. In addition, Granovetter (1983) explores how such exposure affects the cognitive style used in dealing with new and varied social stimuli. 
Based on Coser's (1975) finding that the ability to position oneself in complex social roles is linked to the development of intellectual flexibility, Granovetter (1983) argues that weak social ties lead to complex role sets and the need for cognitive flexibility. Hence, the findings by Coser (1975) and Granovetter (1983) point to a potentially significant relationship between the extent to which the network is characterized by weak versus strong ties by the ego and the ego's ability to come up with rationales for various viewpoints on a given policy.

Our expectation is also based on the fact that social interaction requires resources (Granovetter, 1983). Keeping certain social ties strong comes at the expense of energy or time that might have been devoted to other social ties. Hence, a social network characterized by very close relationships may be associated with less exposure or attention to different arguments from other sources, reducing one's ability and motivation to produce reasoned policy arguments.

Another social network characteristic that might affect citizens' reasoning about policies is the diversity of viewpoints within a social network. A series of studies on social networks have shown the persistence of diverse points of view in such networks (Erisen \& Erisen, 2008; Huckfeldt, Ikeda, \& Pappi, 2005; Huckfeldt, Johnson, \& Sprague, 2004; Huckfeldt \& Mendez, 2008; Huckfeldt \& Sprague, 1995; McClurg, 2006; Mutz, 2002a). The diversity of opinions within a social network is likely to facilitate the dissemination of information and increase tolerance (Mutz, 2002a) while reducing political participation (Mutz, 2002b) and result in more informed decision making (Huckfeldt et al., 2004).

Informed decisions, in turn, might be traced to effortful information processing that involves the consideration of several viewpoints in attitudinally diverse networks. Levitan and Visser (2008) showed that individuals whose networks do not agree with them are more likely to engage in effortful information processing. Furthermore, the attitudinal congruency of the social context in which people are embedded has important implications for the durability and the strength of attitudes, which in turn might point to potential network effects on information processing and cognitive flexibility (Levitan \& Visser, 2009; Visser \& Mirabile, 2004).

Despite the persistence of diverse points of view in social networks, attitude congruency in a social network is much more common. Individuals purposefully construct networks in line with their own political preferences (Huckfeldt \& Sprague, 1984). Motivated reasoning might play a significant role in the formation of attitudinally congruent networks. In forming her network, the ego acts as a motivated reasoner who searches for information in support of the existing priors while contradictory information is ignored or approached with motivated skepticism (Huckfeldt \& Sprague, 1984; Kunda, 1987, 1990; Redlawsk, 2002; Taber \& Lodge, 2006). Hence, the network members are likely to produce confirmatory evidence on political issues that demand less effortful information processing and less cognitive flexibility.

The social context of a network tie is another factor likely to affect how people think and reason about politics. For example, Mutz (2006) finds that most social contexts in which people talk about politics are through work or through relatives, friends, or associates. In contrast, relationships through places of worship, through voluntary associations, and even through neighborhoods constitute a small portion (only 7\%) of the contexts in which people talk about politics. However, the latter produces political agreement much more than communication with relatives, friends, or colleagues do. Hence, because of the relationship between social context and attitude congruency, the extent to which the ego enters into effortful thought processes might also depend on the social context of the network relationships. Moreover, as the number of different social contexts increases within a social network, not only the need to assume complex social roles-hence, the need for cognitive flexibility_increases (Coser, 1975), but also each social role connects the individual to different domains of information flow, which might further increase the need for effortful thought processes.

The number of ties in a social network might also be related to the exposure to new social stimuli. As the number of social ties increases, the likelihood of having ties with varying strengths 
and from different social contexts might also increase. Huckfeldt, Beck, Dalton, and Levine (1995) showed that younger, higher-income, and better-educated people with more organizational ties are more likely to name more discussants. Also, those with more social contacts tend to have more contacts with nonrelatives, and these nonrelative contacts tend to be discussants that are more acquaintances than friends; hence, they have a higher likelihood of having weak ties within their networks. As Granovetter (1983) would argue, these weak ties might further increase the need for cognitive flexibility.

Last but not the least, an important defining characteristic of a social network is the political sophistication of its members. Huckfeldt (2001) argued that people tend to rely on political knowledge, education, and partisan extremity to decide if someone is a political expert and that the level of talk with political experts is independent of disagreement with experts. Hence, politically sophisticated network members are more likely to upload higher-quality information to the network compared to politically naïve and less-educated network members. Moreover, their different viewpoints do not reduce the level of deliberation. As a result, having sophisticated members in the network might increase the exposure to new and varied information, hence putting pressure on the individual for more in-depth reasoning.

Having identified several strands of research in the social networks literature with implications for exposure to new social stimuli, effortful information processing, and cognitive flexibility, we developed an original approach to tease out the independent effects of social network characteristics on citizen thinking and reasoning about political choices. We isolated four dimensions of social networks from the perspective of the ego-cohesiveness, extent, coherence, and sophisticationbased on existing structural social network concepts and tie characteristics such as the strength of social ties, political disagreement, the social context of the network relationship, the size of the network, and the political sophistication of the network members.

Although related, the four concepts introduced here are different from structural concepts in the social networks literature in the sense that these concepts reflect how the ego perceives the network as a whole that is composed of network members. Besides, they are substantively distinct. Each one is related to a different aspect of information flow and processing that originates from a political discussion network: attachment to the information source, the degree of the multiplicity of the information source, the information's potential cognitive challenge to the ego's world view, and the sophistication of the potential political content of information.

For instance, Granovetter (1973) considers the strength of a social tie a function of "the amount of time, the emotional intensity, the intimacy (mutual confiding), and the reciprocal services which characterize the tie" (p. 1361) and argues that weak ties require cognitive flexibility. In this article, we use the concept "network cohesiveness" to represent the degree to which the ego perceives the network as characterized by strong attachment to network members.

Similarly, "network extent" refers to the extent to which the ego could reach potential sources of varied social stimuli via her social network. Both the number of network members and their varied social contexts factor into the ego's coverage of the potential sources of information in her social space. A network with multiple members from multiple social contexts is more likely to have weak ties, involve different social roles, and increase the need for effortful thought processes compared to a small network with relationships from a single social context.

We define "network coherence" as the degree to which the ego considers the network politically homogenous from her perspective. The level of agreement on political issues between the ego and individual network members would affect the ego's sense of network-level political homogeneity. However, network coherence is different from exposure to different views in the network, which would have indicators of ego-alter difference on a single issue, identity, or political choice dimension (Mutz, 2002a). Coherence, on the other hand, stands for the ego's summary judgment on network level similarity across several issues, choices, and identities, i.e., in political world view. 
The last concept, "political sophistication of the network," refers to the extent to which the ego considers the network members as knowledgeable and involved in politics. The level of political interest, involvement, and education of network members affect the ego's sense of the level of political sophistication in her social network.

Neither in our concepts, and consequently, nor in the measurement stage, do we emphasize nonego network members' perceptions vis-à-vis each other. We constructed our concepts egocentrically, and we believe that between network members' relationships as perceived by the ego are a function of the ego's perception of the relationship between herself and each network member. Our focus on the ego's network perception contributes to the study's theoretical coherence, given the subject matter of individual thought quality, which depends on the ego's perception of policies.

In addition to the network concepts introduced here, another novel aspect of the article from the point of view of the social networks literature is its dependent variable: quality of political thinking. Next, we define the concept and discuss the relevant literature.

\section{Quality of Political Thinking}

The public's lack of information on politics is well documented in the literature (Campbell et al., 1960). Yet, despite their informational limitations and their tendency to function as "cognitive misers" (Fiske \& Taylor, 1991), citizens use the little information they have and employ a number of cognitive heuristics (Kahneman, Slovic, \& Tversky, 1982; Nisbett \& Ross, 1980) to become adept in politics. Reaching the threshold of "good enough" is established as the deciding factor in evaluating democratic citizenry (Page \& Shapiro, 1992). Citizens ponder politics, and they reason about issues and policies with limited information and cognitive abilities.

Once they reason, however, it is possible to observe three closely associated characteristics that represent whether an individual's political thinking is rich and causal. Accordingly, we define quality of political thinking as the extent to which an individual can express knowledge on political issues and concepts, observe the causal connections in political issues, and differentiate among the distinct dimensions of issues and the alternative ways of approaching a potential political problem. Our approach to understanding the variation in political thinking is rooted in social psychological attempts to differentiate people on the basis of cognitive rules employed to process and analyze information (McGuire \& McGuire, 1991; Nisbett \& Ross, 1980; Tetlock, 1985).

First, in order to differentiate people on the basis of the cognitive rules they employ to make sense of a political issue, they should at a minimum be able to produce some thoughts. Second, these thoughts may include certain antecedent phenomena that may or may not lead to certain consequences. In other words, the individual may engage in cause-and-effect-based thinking about competing policy proposals or other political decisions.

Explorations on the origins of cause-and-effect-based thinking point to people's tendency to rationalize their feelings or priors in producing antecedent or consequence-related thoughts. For example, Sniderman, Brody, and Tetlock (1991) show that citizens develop their attitudes on an issue first by appraising their feelings, then by seeking out the reasons substantiating the antecedents of the issue, and finally, they form their opinion. Sniderman et al.'s (1991) definition of attitude formation relies on the likability heuristic, which in turn promotes the reasons one could use to substantiate a policy preference. In a similar vein, research on motivated reasoning posits that in support of their priors, individuals would call to mind confirming reasons while ignoring opposing information (Kunda, 1990).

A number of studies in political psychology have looked at the effects of causal thinking on political evaluations. Rosenberg (2002) investigates the structure of political thinking and reasoning and shows that citizens differ in how-if at all-they think causally. The more one thinks in causal 
terms - citing antecedents and consequences of an event and their interaction - the more accurate their predictions and evaluations are on political issues. Bassili and Roy (1998) similarly find that thinking of an anticipated consequence of a policy strengthens one's policy evaluations.

Causal associations among thoughts and events have also been used in the decision-making and framing literature. Particularly, research by Pennington and Hastie $(1992,1993)$ demonstrates that a coherent story built upon a cause-and-effect relationship in juror decision-making procedures has proven to be parsimonious and the most preferred method. Similarly, Berinsky and Kinder (2006) find that events framed as a good, coherent story (in a cause-and-effect relationship) are more effective in comprehension, recall, and opinion expression, through which citizens make sense of politics.

The third characteristic that represents the quality of political thought is the individual's ability to engage in multidimensional and relational thinking in approaching a potential political problem, i.e., the degree of the thoughts' integrative complexity. Integrative complexity is an extensive measure of thought quality confirmed across several previous studies (Jost, Glaser, Kruglanski, \& Sulloway, 2003; Tetlock, 1983, 1984). As defined by Tetlock (1985), the integrative complexity of arguments entails two dimensions: differentiation and integration. While differentiation refers to the number of different issue dimensions used in thinking about an issue, integration refers to how the individual discusses the associations among these dimensions. Thus, because of the integration dimension's emphasis on associations, argument quality goes hand in hand with the degree of causal thinking.

In this article, instead of measuring political thought quality by either one of the three indicators, we chose all three. The approach is based on the expectation that the distinct processes involved in multidimensional and relational thinking in politics on the one hand and the ability to come up with thoughts and rationales on the other might be differentially affected by one's social network characteristics. Below, we present the hypotheses on the effect of social networks on the quality of political thinking.

\section{Hypotheses}

Given the lack of prior research directly linking social networks to the quality of political thinking and reasoning, we focus on the network concepts developed above in constructing our theoretical hypotheses. We believe that the evidence in the literature-which links the strength of social ties, the level of disagreement, the social context of network ties, and the political sophistication of network members to increased need for cognitive flexibility and effortful information processing - justifies our expectation of significant relationships between perceived network cohesiveness, extent, coherence, and sophistication on the one hand and the quality of political thinking on the other.

We propose a separate hypothesis for each network dimension. The quality of thinking about policies is represented by the number of policy-relevant thoughts, the causality of these thoughts, and their integrative complexity. ${ }^{2}$ The three variables serve as dependent variables at the hypothesistesting stage.

H1: Network cohesiveness reduces the quality of thinking about policies.

\footnotetext{
${ }^{2}$ Testing separate hypotheses on the relationship between social networks and political thinking helps us explore an unknown territory better compared to a model test. Building a theoretical model of network effects on political thinking would be a future step toward constructing a process theory of political thinking.
} 
Individuals who perceive themselves as embedded in webs of cozy relationships are less likely to expose themselves to new and varied social stimuli and less likely to devote personal resources to maintain weak ties that are sources of such stimuli. In turn, they are less likely to feel a pressure for sophisticated political thinking.

H2: Network extent improves the quality of thinking about policies.

Having a better reach to political information via many social contacts from various social contexts might create the conditions for an increased need for cognitive flexibility, which in turn might be related to one's ability to engage in rich and causal political reasoning.

H3: Network coherence reduces the quality of thinking about policies.

Individuals who consider their social networks politically homogenous are less likely to have the motivation to seek out and be exposed to different political arguments. This in turn might reduce the quality of thinking about policies.

H4: Network sophistication improves the quality of thinking about policies.

The hypothesis follows from the positive effects of having political sophisticates in one's social network on the individual's ability to reach high-quality and additional political information.

In addition, we expect that individuals' prior attitudes on an issue and their issue-relevant political knowledge will affect the quality of thoughts on the policy. Crystallized beliefs on the desirability of policies might reflect past deliberation and exposure to other sources of information. It is likely that people who know more about an issue can at least use a greater number of arguments in the deliberation process.

Another group of factors that might affect political thinking is subtler. Random and incidental influences, some as simple as a single word or picture or image of a candidate, that are ever existent in the political environment, alter decisions on issues (Erisen, Lodge, \& Taber, forthcoming; Lodge \& Taber, 2005) and candidate-based judgments (Marcus, 1988; Redlawsk, Civettini, \& Lau, 2007) in addition to promoting effective heuristic (Lau \& Redlawsk, 2001) and motivated reasoning (Lebo \& Cassino, 2007; Taber \& Lodge, 2006). As Damasio's (1994) seminal work on the interaction of cognition and emotion shows, politics is as much about emotions as it is about thinking (Brader, 2006; Lodge \& Taber, 2000, 2005; Marcus, Neumann, \& MacKuen, 2000; Redlawsk, 2006). Existing research shows that the interaction of cognition and emotion can be a constructive force shaping individual behavior (Marcus, 2003).

Accordingly, we consider emotion and affect influential in political thinking. In testing the hypotheses on social networks laid out above, controlling for such effects is essential. In fact, these affect-laden contextual cues may trigger better or worse reasoning since negative or positive visual cues (related or unrelated to the issue at hand) might lead the individual to more or less effortful thought processes. ${ }^{3}$ To address this possibility, we presented pictures related to energy policy (either promoting alternative energy resources or promoting oil as an energy resource) and controlled for their effects.

\footnotetext{
${ }^{3}$ In our study, we introduced incidental emotional cues that are contextually related to the policy domain (for a similar approach see Brader, Valentino, \& Suhay, 2008) to control for how news and information are presented by the media and perceived as relevant by citizens. These contextually relevant incidental emotional cues may make certain information more accessible (Cassino \& Erisen, 2010).
} 


\section{Research Design}

To test the hypotheses, we needed data on political discussion networks and also thought listings on policies that would generate data for measuring thought quality. In order to obtain both, we conducted an experimental study at Stony Brook University Laboratory for Political Research and embedded a survey in the design to measure the participant's network characteristics. All participants in the experiment were undergraduate students in political science courses: $(N=111,51 \%$ male, $46 \%$ white, $43 \%$ Liberal, 19\% Conservative). On arriving at the lab and following consent procedures, participants were taken to separate experimental rooms and seated in front of personal computers.

The participants' first task was to answer questions on their social networks' cohesiveness, extent, coherence, and sophistication. Their second task was to report their attitudes on the target issue-energy policy. Item batteries asked for the participants' overall evaluations of the issue and the attitude strength dimensions of accessibility, certainty, importance, knowledge, and relevance (Krosnick \& Petty, 1995; Wegener, Downing, Krosnick, \& Petty, 1995). Third, participants were told that they would see frames from recent news broadcasts on a political issue. Participants were not told what the issue would be; they were just instructed to look closely to the presented pictures. At this step, either pro-oil or proalternative-energy pictures, which determine the participant's treatment condition, were presented (a between-subject experimental design). ${ }^{4}$ Each treatment condition (prooil or proalternative energy) included four frames on the energy issue that were randomly presented on the computer screen for one second per picture. Those in the neutral condition skipped this section and continued to the next section.

At the fourth step, we engaged each participant in a thought-listing procedure (Cacioppo \& Petty, 1981; Lane, 1969; Zaller \& Feldman, 1992). Following exposure to four visual images (or no pictures for the control group), an issue-related public policy appeared on the computer screen with an empty response box below. ${ }^{5}$ The response box remained on screen until the participant finished typing the response. Each participant had the opportunity to type up to seven thoughts or statements in separate response boxes. If participants concluded their statements before reaching the seventh response box, they were able to skip to the next policy statement. After this section, participants answered questions on political knowledge and demographics. Finally, participants were asked questions to verify the purposes of the study. None of the participants reported any suspicion of our aims. The study took 25-30 minutes to complete, on average.

\section{Measures}

\section{Social Network Dimensions}

The measures for social network effects constitute our main independent variables in the regression analyses reported below. The participants' first task in the study was to answer survey items on their social networks. The survey items were taken from the social network batteries of the American National Election Studies (ANES) 2008-2009 panel study, the ANES 2008 time-series study, and the ANES 2006 pilot study. ${ }^{6}$

\footnotetext{
${ }^{4}$ These frames were either promoting alternative energy methods (referring to the positive condition for alternative energy methods) or promoting traditional methods (such as coal, oil, nuclear energy, etc.).

${ }^{5}$ We randomly presented four policies on the issue of energy to the participants. The prompts for the proalternative energy policies were: "Government should ensure that the majority of our electricity comes from renewable sources," and "Government should support the construction of natural gas pipelines." The prompts presented on the computer screen for the pro-oil policies, were: "Government should prioritize our energy needs in national wildlife refuges with oil resources," and "Government should protect oil-dependent industries such as car manufacturing."

${ }^{6}$ See the appendix for the exact question wording.
} 
The measures presented below have some affinity to existing network measures in the literature. This is primarily because their corresponding concepts were developed based on existing works in the social networks literature that have implications for political reasoning. Their difference, as well as their added value, lies in the extent to which they reflect the new network concepts and the measurement strategy used in the article.

First, we argue that each measure better reflects the concept it belongs to than any other existing measure in the literature. The measures are based on clear and mutually exclusive conceptual definitions that focus on the informational value of perceived political discussion networks. Each measure reflects a different aspect of information flow from one's network, such as attachment to the information source, the degree of the multiplicity of the information source, the information's potential cognitive challenge to the ego's world view, and the sophistication of the potential political content of information. Moreover, distinguishing between perceived and objective networks helps streamline the measurement stage by leading to strictly perceptual egocentric measures of network effects.

Second, we consistently distinguished between the quantity of political interaction and its quality in building the measures. We focused on quality as each network variable aims to capture a unique aspect of information that emanates from a specific type of network characteristic. Hence, in building the new measures we followed a measurement strategy where we reflect the quality of the corresponding concept by multiplying the measures of the indicators in the concept to produce a single measure for each network contact. The contact measures are then averaged to reflect the ego's perception of the network as a whole composed of contacts. This strategy has been used for all network measures except "coherence," as discussed below.

Network Cohesiveness. First, we constructed a measure for how the ego perceives the strength of a single social tie based on two survey items: a question on the feeling of closeness toward a network member, measuring the response on a 1-5 scale, and another question measuring the frequency of contact with the network member. We took the product of the two measures for each contact. We posit that feelings of attachment multiplied by frequency of contact represent the degree of attachment in a network relationship. Second, in order to create the network level variable, we averaged the scores the network members received in the first step. The final measure ranges from 0 to 155 , where low figures refer to weak perceived network cohesiveness and high figures represent strong perceived network cohesiveness (Mean $=69$; $\mathrm{SD}=39$ ).

Although Granovetter (1973) defines the strength of a tie as a function of, among others, the frequency of contact and the strength of attachment, because such relationships are typically found in friendship or relative networks, some studies have focused on the social context of network relationships. For instance, Huckfeldt et al.'s (1995) measure of a cohesive social group is relatives or close friends. Although frequency of political talk shows up in some studies as a single ordinal item (e.g., Mutz, 2002a), it is not used for the purposes of representing Granovetter's (1973) definition of the strength of a tie. Hence, our measure's strength comes from directly including the two most important indicators of the strength of a relationship, and its exclusion of social context as part of attachment.

Network Extent. The network extent measure is based on two survey items, one asking the number of social ties and the other asking the social context of the relationship, i.e., whether the social tie is from family or whether the ego met the social tie at school, work, neighborhood, or place of worship. We first developed a coding scheme to assign scores to the networks based on the multiplicity of different social contexts in the network. ${ }^{7}$ The resulting scores measure the reach of the

\footnotetext{
${ }^{7}$ The survey items on political networks elicited information from the respondents on a maximum of four network members. The following multiplicity of social context scores were assigned to the respondents: $5=$ all contacts are from different social contexts; $4=$ two contacts from the same context, third and fourth are from different social contexts; $3=$ two pairs of the same social context; $2=$ three contacts from the same social context, fourth contact from different social context; $1=$ all contacts from the same social context.
} 
network to different social contexts on a 1-5 scale. We multiplied the score by the number of political contacts mentioned by the respondent. This resulted in a network extent measure that ranges from 1 to 24 (Mean: 11; SD: 6).

Existing measures that have affinity to this new measure are categorical social context indicators and the number of contacts variable commonly used in the literature. Used separately, these measures can't produce the variance representing the degree of exposure to potentially social context specific information from multiple social sources.

Network Coherence. We used the ego's reports on the political ideology of each one of her network contacts measured on a 1-7 scale, and her self-reported ideology measured on the same scale. We took the absolute value of the ideological distance between the ego and each contact and averaged the distances to find the political coherence of the network from the perspective of the ego. The resulting measure ranges from 0 to 4.75 with low figures representing incoherence of ideological viewpoints and high figures representing strong coherence of ideological viewpoints (Mean: 1.85; SD: 0.97).

We argue that the average of the ego's perceived ideological distance to alters is a better summary measure of the degree to which the ego perceives the network as sharing similar political world views than party-ID or vote-choice-based measures of diversity or disagreement. First of all, disagreement, diversity, and coherence-although related-are separate concepts. Moreover, compared to the ego-alters similarity of party-ID or vote choice, ideological similarity is more likely to make political world views in a network resemble one another. In addition, given our sample's level of political information, possible concerns about whether the respondents know what political ideology is are also minimized.

Network Sophistication. We constructed a composite index of network sophistication based on survey items measuring political interest, attention, and activities of the network members. We weighted the index with the education level of the network member. Another measurement strategy would be to use the average level of political knowledge that egos perceive in their network discussants (McClurg, 2006). However, we wanted to reflect the leverage the contact's education has in how much the ego pays attention to information coming from a politically involved contact. We averaged the sophistication scores of the social network members to create a measure for the perceived sophistication of the network. In the final measure (ranges from 5 to 53), low figures refer to weak perceived sophistication levels for the network and high figures refer to strong perceived sophistication (Mean: 27; SD: 11).

We believe that the four measures, and the concepts they follow from, are distinct from each other such that they could create a multidimensional space to place a given perceived political network. The correlation matrix reported in Table 1 supports this claim. No single measure of network quality is significantly correlated with another measure of network quality. The lack of

Table 1. Correlation Matrix of Social Network Quality Measures

\begin{tabular}{lcccc}
\hline & $\begin{array}{c}\text { Network } \\
\text { Cohesiveness }\end{array}$ & $\begin{array}{c}\text { Network } \\
\text { Extent }\end{array}$ & $\begin{array}{c}\text { Network } \\
\text { Coherence }\end{array}$ & $\begin{array}{c}\text { Network } \\
\text { Sophistication }\end{array}$ \\
\hline Network Cohesiveness & 1 & & \\
Network Extent & 0.08 & 1 & 1 & 1 \\
Network Coherence & $(0.38)$ & 0.05 & \\
Network Sophistication & 0.13 & $(0.62)$ & -0.14 & $(-0.15)$ \\
\hline
\end{tabular}

Note. Pearson correlation coefficients are provided in each cell with $p$-values in the parentheses. 
significant correlations is particularly important for isolating the impact of different aspects of a given network in the regression analyses reported in the Results section.

\section{The Quality of Thinking on Policies}

We have three separate measures on thought quality that correspond to the three indicators discussed in the conceptual definition of the quality of political thinking.

Number of Thoughts. Our first dependent variable on the quality of thinking is the total number of thoughts that one can recall on four energy policies (two proalternative energy and two pro-oil). ${ }^{8}$ Those participants who listed a higher number of thoughts are considered more knowledgeable since they are able to retrieve more information on the issue from memory (Berinsky \& Kinder, 2006; Green, Visser, \& Tetlock, 2000). Two coders, unaware of the research hypotheses, coded the thoughts listed by the participants. Coder reliability was 0.97 on the task of categorizing the thoughts and generating the-number-of-thoughts measure. The number of thoughts ranged between 0 and 26 (Mean: 8; SD: 6.52).

Number of Causal Thoughts (Rationales). Next, we turn to one's ability to think in causal chains and report rationales on a policy. Thinking and reasoning get stronger as one uses reasoning chains - antecedent and consequence relationships, which we call rationales - on the issue. In order to create the measure of rationales, the thoughts collected via the thought-listing task procedure in the study were categorized into two groups across four energy policies: the thought is a rationale (causes or effects of the policy), or the thought is not a rationale (feelings toward the policy, agreement or disagreement with the policy, the likelihood of the policy actually happening, etc.).

For instance, the following thoughts were coded as rationales: "Drilling for oil may constitute a major concern to the environment"; "Global warming harms our life and it's no longer the story of far future"; and "Companies don't take enough responsibility nor enough precautions to prevent accidents." In contrast, the following thoughts are coded as other thoughts (not a rationale): "I have mixed feelings about this one"; "I oppose this proposition"; and "We should move away from gas."

For the total-number-of-thoughts measure explained above, we used all the thoughts listed by the participants, whereas for the rationales measure we only used the number of rationales. As before, two coders unaware of the research hypotheses coded the thoughts listed by the participants. Coder reliability was 0.83: quite high and hence reliable, given the task. We use the averages of these two codes on the policy statements as the measure of rationales in the regression analyses reported below. The number of causal thoughts listed ranged between 0 and 23 (Mean: 3.4; SD: 4.34).

Integrative Complexity of Thoughts. We simply took the thoughts of the participants listed on the policies and had them coded according to the coding scheme proposed by Tetlock (1985) to measure the level of integrative complexity. We used Tetlock's (1985) approach to measure how distinct one's thoughts and arguments are from each other in terms of the various issue dimensions of the policy (differentiation) and how the participant discusses the relationships among the different dimensions of the policy in her listed thoughts and arguments (integration).

For this task, two trained coders unaware of the research hypotheses coded the statements listed by the participants across all energy policies. Thoughts were coded on a scale of 1 to 7 in the following way: 1 stands for low differentiation and low integration; 3 stands for moderate to high differentiation, but low integration; 5 stands for moderate to high differentiation and moderate integration; 7 stands for high differentiation and high integration.

With a score of 1 , the individual is found to create good-bad categories for the events/cases. With a score of 3, the individual recognizes alternative points of view, but does not perceive the relations

\footnotetext{
${ }^{8}$ Only those statements substantively related to the policy are considered as "thoughts." Fewer than $2 \%$ of the thoughts listed by the participants were considered irrelevant.
} 
between them. For instance, the following paragraph, cited by a participant on the policy of governmental support for the construction of natural gas pipelines, is coded at the integrative complexity level of 3: "This would be ideal. Natural gas is a good alternative to our dependency on other sources of energy. This could help in many areas of our society and we need to find more resources before we run out of options."

With a score of 5, the individual develops an explicit comparison rule to contrast the alternative perspective on the issue. For example, the following thoughts cited on one of the policies are coded at the score of 5: "It is important that we start to use other sources of energy than gas and oil. We have to start sometime or we will be in even more trouble than we are now. This is also important because it will have a beneficial impact on the environment. New jobs will be created as a result of utilizing these new sources of energy. There needs to be enforcement on this issue because people won't stop their dependence on oil and gasoline on their own."

With a score of 7 , the individual uses complex rules to compare and contrast alternative perspectives on the issue. Hence, as the individual recalls more information about the issue or policy and organizes the causal links among the thoughts on the topic, she will present a better understanding of the antecedents and consequences of the alternatives.

Both coders assigned an integrative complexity score for each participant on the statements that the participant cited on a single policy. Coder reliability was 0.94 for the task of rating participants' responses, according to the Integrative Complexity coding scheme. ${ }^{9}$ Next, we created the dependent variable of integrative complexity of thoughts by averaging the participants' integrative complexity scores across four policy propositions and across the coders. The integrative complexity score ranged between 1 and 5.5 (Mean: 2.4; SD: 1.33).

\section{Control Variables}

The control variables account for the participants' prior attitudes, political knowledge, and the treatment conditions in the regression analyses. We created the prior attitude measure from the item batteries that asked for the participants' overall evaluations of the issue (ranging from -3 to +3 ) and the attitude strength dimensions of accessibility, certainty, importance, knowledge, and relevance (ranging from 0 to 1). The product of the two, the position and the strength of the attitude, created the prior attitude variable (Fishbein \& Ajzen, 1975). Higher scores on the prior attitude measure point to strong proalternative energy issue stands whereas lower scores point to weak proalternative and strong pro-oil energy issue stands.

The political knowledge measure was created from the participants' responses to open-ended factual questions on the issue of energy. ${ }^{10}$ An independent coder categorized the participants' responses into a $0-1$ scale, where 1 represents a correct response. We summed the correct responses to generate the political knowledge measure.

In addition to these two control variables, we controlled for the potential impact of two types of affect-laden visual frames in the political environment by including two dummy variables that stand for the proalternative energy frame and the pro-oil frame, with no frame as the base category.

\section{Results}

In all of the statistical analyses reported below, we used the four measures of the social network concepts—cohesiveness, extent, coherence, and sophistication-as the main independent variables.

\footnotetext{
${ }^{9}$ Approximately $4 \%$ of the statements listed by the subjects were not given an integrative complexity score because the statements were simply evaluative and did not have any conceptual structure.

${ }^{10}$ These questions were on the identification of the countries that the United States imports oil from, the new energy resources that could reduce America's consumption of oil, the clean pass vehicle, the percentage share of nuclear reactors in generating the nation's electricity, and finally the price of gas (on average and in the area) during the days of the study.
} 
Table 2. Network Cohesiveness Reduces the Number of Thoughts on Energy Policies

\begin{tabular}{lccc}
\hline Variable & \multicolumn{3}{c}{$\begin{array}{c}\text { Number of Thoughts on } \\
\text { Energy Policies }\end{array}$} \\
\cline { 2 - 4 } & Coefficient & S.E. & $t$-value \\
\hline Network cohesiveness & -0.05 & 0.01 & $-2.78^{* * * *}$ \\
Network extent & 0.02 & 0.11 & 0.15 \\
Network coherence & 0.27 & 0.70 & 0.38 \\
Network sophistication & 0.03 & 0.06 & 0.57 \\
Prior attitude & 1.36 & 1.20 & 1.14 \\
Political knowledge & -0.48 & 0.79 & -0.62 \\
Pro-oil picture & 2.29 & 1.59 & 1.45 \\
Pro alternative energy picture & 2.41 & 1.60 & 1.51 \\
Constant & 8.13 & 2.90 & $2.80^{* * * *}$ \\
& $N=101$ & & \\
& $R^{2}=.12 ; F(8,92)=1.55 ; p<.2$ \\
\hline
\end{tabular}

Note. Coefficients are obtained from the OLS regression of the number of thoughts on energy policies on the independent variables.

Robust standard errors are presented. Asterisks denote $*=p<.1$; $* *=p<.5 ; * * *=p<.01$.

Prior attitudes on the energy issue, political knowledge, and the two dummy variables for the two treatment conditions are the control variables. The number of thoughts, the number of causal thoughts, and the integrative complexity of thoughts serve as the dependent variables. We employed the Ordinary Least Squares (OLS) method with robust standard errors for hypothesis testing.

\section{Distinct Effects on the Quality of Thinking}

The regression results for the effect of social networks on the number of thoughts on four energy policies (two proalternative energy policies and two pro-oil policies) are presented in Table 2 . The major finding of the regression analyses is that as network cohesiveness increases, the number of policy-related thoughts decreases significantly. It seems that having a network characterized by frequent contact with and very close feelings toward the members is associated with fewer ideas and considerations one can bring to bear on the energy issue. ${ }^{11}$

Although a unit change in network cohesiveness seems to have a relatively small impact on the number of thoughts $(\beta=-.05)$, a change of one-quarter on the scale of cohesiveness would generate a two-thoughts decrease. In fact, an increase from the minimum to the maximum value on the cohesiveness scale is associated with a 6.9 points decrease in the total number of thoughts, holding other variables in the model constant. Given the range of the total number of thoughts, the impact of cohesiveness is a considerably large one. In addition, other social network variables, particularly network extent and sophistication, do not significantly affect the total number of thoughts. The results, however, show how cohesiveness weakens policy-related thinking only for one of the characteristics that define the quality of political thinking. Next, we turn to the second characteristic, the ability to observe the causal connections, the rationales, on political issues.

The regression model with the number of causal thoughts as the dependent variable produces similar results. We find a significant negative relationship between network cohesiveness and the

\footnotetext{
${ }^{11}$ We also ran two regression models with the same independent variables but with the total number of thoughts for the two proalternative energy policies and the total number of thoughts for the two pro-oil policies separately as the dependent variables. The pattern of results remains the same.
} 
Table 3. Network Cohesiveness Reduces the Number of Causal Thoughts on Energy Policies

\begin{tabular}{lccc}
\hline Variable & \multicolumn{3}{c}{$\begin{array}{c}\text { Number of Causal Thoughts } \\
\text { on Energy Policies }\end{array}$} \\
\cline { 2 - 4 } & Coefficient & S.E. & $t$-value \\
\hline Network cohesiveness & -0.03 & 0.01 & $-3.34^{* * *}$ \\
Network extent & -0.02 & 0.06 & -0.29 \\
Network coherence & -0.12 & 0.44 & -0.28 \\
Network sophistication & 0.01 & 0.04 & 0.16 \\
Prior attitude & 1.10 & 0.79 & 1.39 \\
Political knowledge & 0.02 & 0.38 & 0.07 \\
Pro-oil picture & 0.99 & 0.87 & 1.13 \\
Pro alternative energy picture & 1.52 & 1.06 & 1.42 \\
Constant & 3.89 & 1.99 & $1.95^{*}$ \\
& $N=101$ & & \\
& $R^{2}=.11 ; F(8,92)=2.09 ; p<.04$ \\
\hline
\end{tabular}

Note. Coefficients are obtained from the OLS regression of the number of causal thoughts on energy policies on the independent variables.

Robust standard errors are presented. Asterisks denote $*=p<.1$; $* *=p<.5 ; * * *=p<.01$.

number of causal thoughts that individuals can produce on energy policy. Participants with cohesive social networks not only produced fewer numbers of policy-relevant thoughts overall, but as the results presented in Table 3 show, their causal arguments also became fewer for the same number of overall thoughts compared to the participants with less cohesive networks.

Once again, other network characteristics are insignificant predictors of thought quality, as indicated by the number of causal thoughts. The impact of network cohesiveness is a considerably large one. An increase of one-quarter on the network cohesiveness scale would generate slightly more than a "one-causal-thought" decrease on the number of causal thoughts one can remember, holding other variables in the model constant. An increase from the minimum to the maximum value on the cohesiveness scale is associated with a 4.3 points decrease in the number of causal thoughts.

The number of thoughts and rationales are perhaps measuring the quality of thinking in a single-issue dimension of the policy. To see whether the effect of cohesiveness would last for a more developed measure of the quality of thinking, we turn to the integrative complexity of thoughts. The regression model with integrative complexity of thoughts as the dependent variable yields similar results (see Table 4). Once again, network cohesiveness has a significant negative impact on the quality of political thinking. A one-quarter-point increase on the network cohesiveness scale generates a half-point decrease (on the 1-7 scale) in the integrative complexity of thoughts, holding other variables in the model constant. An increase from the minimum to the maximum value on the cohesiveness scale is associated with a 1.1 point decrease in the integrative complexity of thoughts. ${ }^{12}$

In addition to the consistent negative impact of network cohesiveness, we find that the network extent improves the integrative complexity of thoughts on energy policy. Communicating with a large number of people from different social contexts—-such as family, work, or school—increases the chances of being exposed to different dimensions of a given policy, which in turn would support

\footnotetext{
${ }^{12}$ We also conducted the same regression model with standardized variables and found that the effect of network cohesiveness on the number of thoughts, the number of causal thoughts, and the integrative complexity of thoughts is 10,11 , and 2.5 times greater respectively (on average) than the three remaining network dimensions.
} 
Table 4. Network Cohesiveness Reduces the Integrative Complexity of Thoughts on Energy Policies

\begin{tabular}{lccc}
\hline Variable & \multicolumn{3}{c}{$\begin{array}{c}\text { Integrative Complexity of } \\
\text { Thoughts on Energy Policies }\end{array}$} \\
\cline { 2 - 4 } & Coefficient & S.E. & $t$-value \\
\hline Network cohesiveness & -0.01 & 0.00 & $-1.80^{*}$ \\
Network extent & 0.04 & 0.02 & $1.89^{*}$ \\
Network coherence & 0.01 & 0.15 & 0.10 \\
Network sophistication & 0.01 & 0.01 & 0.58 \\
Prior attitude & 0.74 & 0.26 & $2.88^{* * *}$ \\
Political knowledge & 0.16 & 0.14 & 1.17 \\
Pro-oil picture & 0.22 & 0.32 & 0.67 \\
Pro alternative energy picture & 0.27 & 0.33 & 0.81 \\
Constant & 1.05 & 0.57 & $1.82 *$ \\
& $N=95$ & & \\
& $R^{2}=.22 ; F(8,86)=3.07 ; p<.004$ \\
\hline
\end{tabular}

Note. Coefficients are obtained from the OLS regression of the integrative complexity of thoughts on energy policies on the independent variables.

Robust standard errors are presented. Asterisks denote $*=p<.1$; $* *=p<.5 ; * * *=p<.01$.

a multidimensional and relational style in thinking. ${ }^{13}$ Relatedly, network extent might have decreased the effect of network cohesiveness, suggesting a possible interaction between the two indicators. We examine this possibility in the next section.

Another important effect on the integrative complexity of thoughts is the strengthening impact of prior attitudes. Those who have strong prior attitudes on the issue might have already engaged in a rationalization process involving major dimensions of integrative complexity (Kunda, 1987). Because of the importance of the energy issue, the public has been given a variety of reasons for or against the increased use of alternative energy over time, and a segment of the public might have used these arguments to rationalize their policy positions. Equally important, the prior attitude effects suggest that the integrative complexity measure is another component of quality of thinking but certainly distinct from the previous two indicators (number of thoughts and rationales).

We also considered the possibility that the wording of the policies might be perceived in such a way (as something that the government should do) that could generate bias in the participants' responses. It could be the case that conservatives were more immediately on the defensive because they would be more opposed to government intervention than liberals. To that end, we compared three ideological groups on our dependent variables and did not find significant mean differences across the liberal, moderate, and conservative groups.

In sum, these results support the alternative hypothesis that network cohesiveness reduces the quality of thinking about policies. The simulation results presented in Table 5 show the expected values of the dependent variables for the minimum, mean, and maximum values of the network cohesiveness variable (Tomz, Wittenberg, \& King, 2003). Network cohesiveness has a consistent,

${ }^{13}$ However, since we have not found consistent results on network extent, we believe that this independent finding could be a policy-statement-related effect. To measure the possibility of policy-based differences (pro-oil vs. proalternative energy) in the quality of integrative complexity, we conducted two separate regression analyses with the same independent variables. The dependent variables were generated as an average of the integrative complexity scores for the respective group. We found a statistically significant effect $(p<.05)$ of the network extent on the integrative complexity scores only for the pro-oil energy policies. 
Table 5. The Expected Values of the Number of Thoughts, the Number of Causal Thoughts, and the Integrative Complexity of Thoughts Decrease as Network Cohesiveness Increases from Its Minimum Value to Its Mean, and to Its Maximum Value, Holding Other Variables at Their Means

\begin{tabular}{lccc}
\hline Dependent Variable & \multicolumn{2}{c}{ Changes in the Expected Value of the Dependent Variable } \\
\cline { 2 - 4 } & $\begin{array}{c}\text { Cohesiveness at its minimum } \\
\text { (A non-cohesive network) }\end{array}$ & $\begin{array}{c}\text { Cohesiveness } \\
\text { at its mean }\end{array}$ & $\begin{array}{c}\text { Cohesiveness at its } \\
\text { maximum (Extremely } \\
\text { close-knit network) }\end{array}$ \\
\hline The number of thoughts & 11.3 & 8.2 & 4.4 \\
The number of causal thoughts & 5.4 & 3.5 & 1.1 \\
The integrative complexity of thoughts & 2.9 & 2.4 & 1.8 \\
\hline
\end{tabular}

negative, and large impact on all three dependent variables representing the quality of political thinking. However, we find no support for the effect of the other social network variables on the quality of thinking about policies, with the exception of the positive effect of network extent on the integrative complexity of thoughts. ${ }^{14}$

\section{Interaction Effects on the Quality of Thinking}

So far in our analyses we have left out the possible interactions among social network dimensions. Having found the consistently negative impact of network cohesiveness in testing the hypotheses, we continued our regression analyses with controls for the interactive effects of cohesiveness and other network dimensions: network extent, network coherence, and network sophistication. We added three interaction variables to the regression models discussed above.

The results once again point to the importance of network cohesiveness in explaining the quality of political thinking (see Table 6). First, in all but one model (integrative complexity of thoughts), the negative effect of network cohesiveness is maintained while controlling for the interactions. Second, the interaction between network cohesiveness and network extent significantly increases the integrative complexity of thoughts. Third, network extent reduces the harmful effect of network cohesiveness on the number of thoughts one can list on energy policy.

The findings on integrative complexity are worthy of further discussion. Neither network cohesiveness nor network extent seems to have an independent significant effect on the integrative complexity of thoughts. In other words, talking politics with close people in your network-ones you see often-or talking politics with many people from home, work, school, or place of worship does not single-handedly explain the degree to which an individual can see the different issue dimensions involved in a policy or the links among those dimensions. On the other hand, having frequent contact with and attachment to a large number of individuals from various social contexts is associated with an increased ability for multidimensional, relational thinking in politics. It is likely that someone who can sustain very close relationships with many people in various domains of public and personal life has the capacity to use a multidimensional approach in understanding a variety of issues, including those that are political.

When it comes to producing many thoughts on a policy regardless of the policy's issue dimensions, which is more of a memory-intensive task than an analytical one, cohesiveness does have an independent effect that can be reversed to some degree with network extent. The negative independent effect of network cohesiveness on thinking in terms of antecedents and consequences is

${ }^{14}$ As a final test of our findings, we conducted power analysis through the G*Power software (Faul, Erdfelder, Buchner, \& Lang, 2009). Using the number of predictors and the sample sizes shown in Tables $2-4$, we conducted the power analysis at the .05 level of alpha and the effect size of .15, a conservative level for our analysis. All power analyses independently conducted on all our models predicted strong support (above the .95 level of power) for our results. 


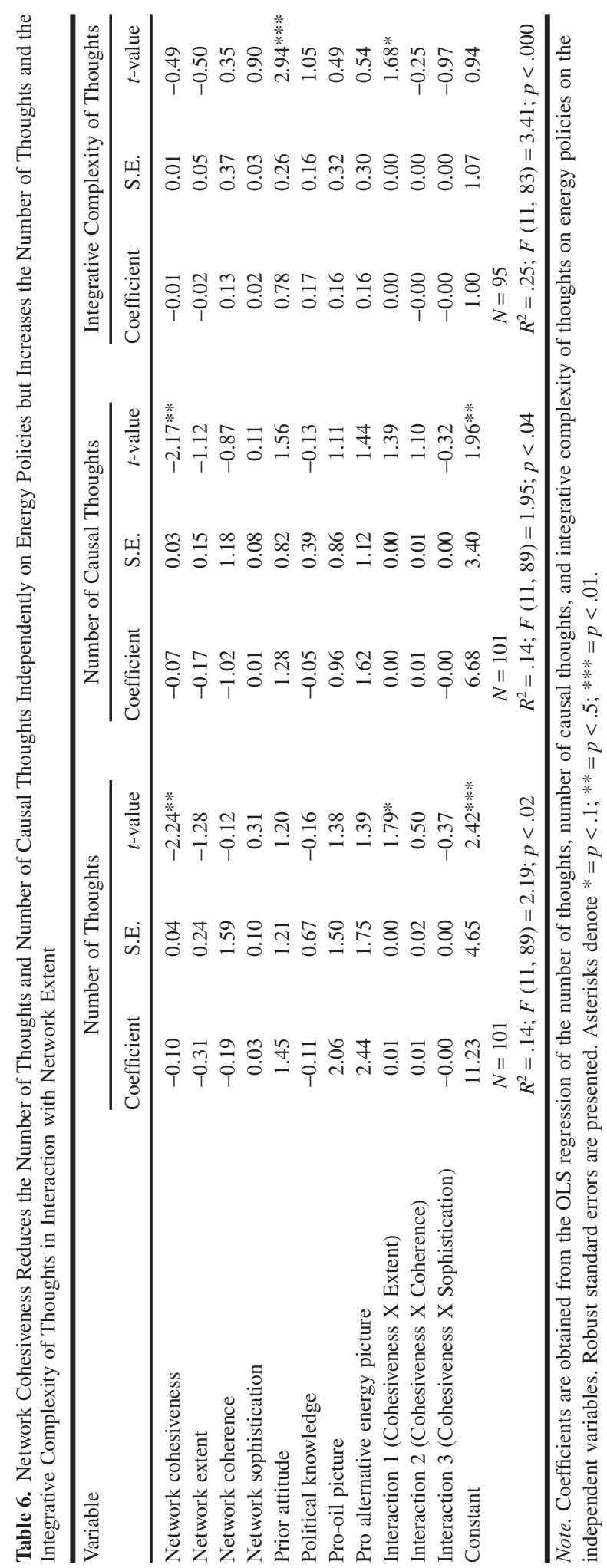


maintained while controlling for the interactions. These findings might point to the distinct processes involved in multidimensional and relational thinking in politics on the one hand and the ability to come up with thoughts and rationales on the other. We believe that these findings are also important for the study of social networks as they illustrate how the independent and interactive effects of social network characteristics can be unique depending on the individual-level political phenomenon explained in a study.

Finally, we acknowledge that a possible limitation of our study would be the use of a sample of university students. ${ }^{15}$ On this matter, in addition to strong supporting evidence for our models from the power analysis, we rely on previous research. Studies with similar goals, similar samples, and similar independent variables showed that it is possible to reach reliable inferences (Levitan \& Visser, 2009; Visser \& Mirabile, 2004) through the proper inclusion of students in survey and experimental research (Mintz, Redd, \& Vedlitz, 2006). We argue that our dependent variables and the main independent variables can be measured with university students (Druckman \& Kam, 2011). ${ }^{16}$ Albeit this possible limitation, we believe that our results are valid on the dampening effects of network cohesiveness on the quality of political thinking.

\section{Discussion}

In this article we introduced new network concepts and a new approach to measuring network effects. First, we chose to focus on the perceived social network, then developed network concepts that highlight the distinct aspects of information flow in a network, translated the network concepts into measurement-ready indicators, and developed the corresponding network measures. We critically questioned the relevance of the existing concepts and measures in the social networks literature for our understanding of the quality of political thinking in particular and the political psychology of social network influence in general. By strictly focusing on the ego's perception and on the dependent variable of the study at the conceptualization stage, we came up with a more parsimonious approach to measuring network effects. Our approach helped us go beyond existing measures that generally assume complete data, which has impeded progress in both experimental and survey contexts where such data are not available.

In fact, there is great potential in the social networks literature for new measures, such as those presented in this article. First, gathering complete network data is costly and its added value might not be high, depending on what is explained in the study. New measures that travel well with less data might enable researchers to examine new research questions, such as the one presented in this article. Second, as political scientists work more on the processes behind observed network effects or introduce new research questions linking different strands of research in political psychology to the study of social networks, new measures will be needed. Current measures in the political discussion networks literature are largely anchored in network concepts that belong to the deliberative democracy framework or social context effects studies. The theoretical basis of the existing network measures might be limiting when it comes to new research questions from a political psychology perspective that require an emphasis on the information flow aspect of social networks.

Equally important, our research introduces a new dependent variable into the study of social network effects: quality of political thinking. We also proposed a measurement strategy for the

\footnotetext{
${ }^{15}$ Our attempt to conduct this research with the ANES data set using a nationally representative sample was unfruitful for two reasons. First, the questions that we intended to ask to measure the quality of political thinking and reasoning were not administered in the ANES surveys. Second, our aim to use open-ended questions that might function as proxies of our dependent variables were unfortunately available in a redacted version only, which would certainly create reliability problems if we were to seek further analyses.

${ }^{16}$ We compared the distribution of the responses to the network items in the 2008-2009 ANES time-series study and the distribution of the responses to the similar items from our sample; the distributions were found to be very similar.
} 
quality of political thinking by focusing on three indicators. The study owes its innovativeness in this respect to its design, which enabled the collection of information on all the relevant aspects of social networks by a survey and made sure that the data from the thought-listing procedure were not artifacts of the particular policy frames.

In addition to the originality of the measurement, the consistent findings contribute to the literature and motivate further research and discussion. Our primary finding is that cohesive networks result in lower-quality thinking. Conversely, those who have occasional contact with and loose attachment to people with whom they talk about politics have richer and more causal thinking on energy policy. Although this conclusion sounds similar to the idea of "the strength of weak ties," our approach to explaining network effects makes it significantly different from what Granovetter (1973) meant by the "strength" that comes with loose contacts.

Cohesiveness as a concept is related to the structural concept of the strength of a tie. However, the idea behind the strength of weak ties (Granovetter, 1973) is that they tend to come from different social contexts; hence, they are bridges to different domains of information. Although this is true for weak ties, in our analyses we controlled for the effects of the multiplicity of social contexts and the number of social contacts by network extent; and the independent effect of network cohesiveness still held true.

Hence, we believe that it is the perception of a cozy web of relations in the social network that explains one's ability to think about policies. It seems that the feelings of strong attachment to one's network members are associated with those traits that underlie low-quality political thinking. On the other hand, the detrimental effect of network cohesiveness on political thinking turns positive when those close relationships in a cohesive network enable the flow of information from an extensive political network that covers many people from various social contexts. Granovetter's (1973) prediction of the strength of weak ties is manifested in the positive effect of the interaction between network cohesiveness and network extent on the integrative complexity of thoughts.

Furthermore, close-knit social networks generate low-quality reasoning regardless of the network's level of political sophistication or the existence of a variety of political views in the network. We believe that the positive effects of having politically sophisticated network members (Huckfeldt, 2001) or the negative effects of having more congruent members (Levitan \& Visser, 2008; Mutz, 2002a) that have been documented in the literature are not evident in our results due to the nature of what is explored in the study: the quality of political thought. The political alignment or the level of sophistication of close contacts may result in exposure to arguments that are different from one's own. However, when it comes to producing a variety of rationales on an issue, repeated exposure to close contacts-hence, to their views and cognitive styles-limits the richness of one's thoughts.

In addition, sustaining a social tie is costly in terms of time and other resources used in social interaction. Strong attachment, both in terms of feelings and the frequency of interaction, may deplete significant social energy and limit the individual's exposure to information about political life from out-of-network sources. Hence, the individual's capacity to produce high-quality thoughts on policies becomes negatively affected by the opportunity cost of maintaining very strong social ties (Granovetter, 1983). In addition, as Coser (1975) and Granovetter (1983) suggest, the motivation for cognitive complexity would be lower in the less-socially complex roles typically found in cozy relationships, which in turn may affect the capacity for political deliberation.

Motivated skepticism may play a role in explaining the mechanism behind the formation of cohesive networks. When exposed to pro and con arguments on any topic, individuals counterargue the contrary evidence and uncritically bolster supporting ones in line with the disconfirmation bias (Kunda, 1990; Redlawsk, 2002; Taber \& Lodge, 2006). When these individuals self-select the source 
of political arguments, they seek confirmatory evidence (i.e., confirmation bias). Both confirmation and disconfirmation biases yield attitude polarization, especially among those with the strongest prior attitudes and the highest levels of political knowledge.

Given our findings, those who talk about politics with people they see often and whom they value are likely to be exposed to the political arguments of their close contacts often. Consequently, they could become more polarized on issues and turn out to support congruent information but oppose incongruent information. As a result, they limit their expression of a variety of arguments, which generates weak political thoughts and deliberation. ${ }^{17}$

The findings are significant from a policy point of view as well. If cozy social networks reduce the quality of thinking, then government policies changing how citizens relate to each other might also change the quality of citizen thinking on policies. Existing political institutions, specifically policies, may also encourage the development of cohesive networks and lead people toward strong social ties, which would trigger the mechanisms discussed above. Policies leading to suburban sprawl and neighborhood segregation, or weak integration policies for immigrants, are all examples of policies that make cohesive networks more widespread by making citizens more dependent on their close-knit groups. Cohesiveness of social networks may eventually generate "social bubbles" that would limit how one communicates with others and reasons about politics.

As the discussion above shows, the insights from this research carry us toward new ways of understanding the political psychology of network influence. Future studies should address the mechanisms behind the dampening effect of network cohesiveness on political thinking. Motivated reasoning may play a role in the formation of cohesive social networks and in reducing the various rationales one can express on a political issue. Hence, it deserves more research in the social networks literature. Also, given political thinking's importance to the quality of political deliberation, it deserves more attention in studies of social network effects.

Finally, we believe that future studies will further perfect the social network measures based on the indicators presented in the article. In fact, the issue of the need for new network measures deserves more discussion in the literature. New measures that go beyond the current conceptual and data limits will contribute to the incorporation of new research questions into the social networks literature. This, in turn, will further our understanding of the links between the individual-level psychological processes behind political attitudes and behavior and the immediate social context the individual is embedded in.

\section{Appendix}

\section{Items Used to Measure Four Distinct Social Network Dimensions}

\section{Network Extent}

Including two dimensions: Social context of network members' relationship (work, family, neighborhood, etc.) and social network size.

1. During the last six months, did you talk with anyone face-to-face, on the phone, by email, or in any other way about politics or did you not do this with anyone during the last six months?

1. Yes, did talk

5. No, did not talk

${ }^{17}$ On this same topic, party identification and political ideology of the individual may reflect the effects of close-knit social ties. Tetlock (1983) previously found that conservatives are generally less integratively complex than liberals, which may affect the quality of political thinking (see Jost et al., 2003). Although in line with our hypotheses, we did not find any evidence for this proposition. 
2. (If yes to Q1 above) What is the first name of the [FIRST / SECOND / THIRD / FOURTH] person who you talked with face-to-face, on the phone, by email, or in any other way during the past six months, about politics?

[Depending on the number of network members the person mentioned, we presented only the respective questions to measure the relevant social network dimension.]

3. Choose one or more of the following: (FIRST / SECOND / THIRD / FOURTH network member name)

1. (Network member name) is a member of my family

2. I know (Network member name) from work

3. I know (Network member name) from my neighborhood

4. I know (Network member name) from my place of worship

5. I know (Network member name) from school

6. Somewhere else?

Network Sophistication

Includes three dimensions: Network members' analytical ability, level of political information, and level of political interest.

[If the Respondent mentioned at least one network member in Q2 above]

1. [NAME 1 / NAME 2 / NAME 3 / NAME 4]'s level of education is best described by

1. 1-8 grades

2. Some high school

3. High school graduate

4. Some college

5. College degree

6. Master's degree

7. Ph.D.

8. Don't know

2. How interested is [NAME 1/ NAME 2 / NAME 3 / NAME 4] in information about what's going on in government and politics?

1. Extremely interested

2. Very interested

3. Moderately interested

4. Slightly interested

5. Not interested at all

6. Don't know

3. How interested are you in information about what's going on in government and politics?

1. Extremely interested

2. Very interested

3. Moderately interested

4. Slightly interested

5. Not interested at all

4. How often does [NAME 1/ NAME 2 / NAME 3 / NAME 4] pay attention to what's going on in government and politics?

1. All the time

2. Most of the time

3. About half the time

4. Once in a while

5. Never

6. Don't know 
5. How often do you pay attention to what's going on in government and politics?

1. All the time

2. Most of the time

3. About half the time

4. Once in a while

5. Never

6. Does [NAME 1/ NAME 2 / NAME 3 / NAME 4] do the following?

1. Attend political meetings, rallies, speeches, dinners, or things like that in support of a particular candidate, party, political cause?

1. Yes

2. No

3. Don't know

2. Give money to candidates, parties, political organizations?

1. Yes

2. No

3. Don't know

3. Reach representatives via letters, phone calls, email, or other means?
1. Yes
2. No
3. Don't know

7. Do you do the following?

1. Attend political meetings, rallies, speeches, dinners, or things like that in support of a particular candidate, party, political cause.
1. Yes
2. No

2. Give money to candidates, parties, political organizations.
1. Yes
2. No

3. Reach representatives via letters, phone calls, email, or other means.

1. Yes

\section{Network Cohesiveness}

Includes three dimensions: Importance given to the contact, frequency of social contact, and frequency of politics-specific contact.

1. How close do you feel to [NAME 1/ NAME 2 / NAME 3 / NAME 4]?

1. Extremely close

2. Very close

3. Moderately close

4. Slightly close

5. Not close at all

2. During the last month, about how many days did you talk to [NAME 1/ NAME 2 / NAME 3 / NAME 4]?

(Open-ended Response)

3. Please think about the relations between two of the people you mentioned. During the last six months, about how many days would you guess they talked to each other? (Open-ended Response) 


\section{Network Coherence}

Includes three dimensions regarding congruence of political attitudes; party ID, ideology, and issue stands.

1. Generally speaking, does [NAME 1/ NAME 2 / NAME 3 / NAME 4] probably think of himself/herself as a Republican, a Democrat, an Independent, or what?
1. Democrat
2. Republican
3. Independent
4. Other

2. (If Republican to Q1 above) Do you think that [NAME 1/ NAME 2 / NAME 3 / NAME 4] is a strong Republican or a not very strong Republican?

1. Strong Republican

2. Not Very Strong Republican

3. (If Democrat to Q1 above) Do you think that [NAME 1/ NAME 2 / NAME 3 / NAME 4] is a strong Democrat or a not very strong Democrat?

1. Strong Democrat

2. Not Very Strong Democrat

4. If [NAME 1/ NAME 2 / NAME 3 / NAME 4] is Independent, does [he/she] think of [himself/ herself] as closer to the Democratic Party or the Republican Party?
1. Closer to Democratic
2. Closer to Republican
3. Neither
4. Don't know

5. In general, how different are [NAME 1/ NAME 2 / NAME 3 / NAME 4] 's opinions about political issues from your own views?

1. Extremely different

2. Very different

3. Moderately different

4. Slightly different

5. Not different at all

6. When it comes to politics, do you usually think of [NAME 1/ NAME 2 / NAME 3 / NAME 4] as

1. Extremely liberal

2. Liberal

3. Slightly liberal

4. Moderate; middle of the road

5. Slightly conservative

6. Conservative

7. Extremely conservative

7. When it comes to politics, do you usually think of yourself as

1. Extremely liberal

2. Liberal

3. Slightly liberal

4. Moderate; middle of the road

5. Slightly conservative

6. Conservative

7. Extremely conservative

8. [NAME 1/ NAME 2 / NAME 3 / NAME 4] is

1. Male

2. Female 
9. What racial or ethnic group best describes [NAME 1/ NAME 2 / NAME 3 / NAME 4]?

1. Asian/Pacific Islander

2. Black

3. Hispanic

4. Native American

5. White

6. Other

10. What racial or ethnic group best describes you?

1. Asian/Pacific Islander

2. Black

3. Hispanic

4. Native American

5. White

6. Other

11. What is the yearly household income of [NAME 1/ NAME 2 / NAME 3 / NAME 4]?

1. Less than $\$ 10,000$

2. $\$ 10,000-\$ 19,999$

3. $\$ 20,000-\$ 29,999$

4. $\$ 30,000-\$ 39,000$

5. $\$ 40,000-\$ 49,999$

6. $\$ 50,000-\$ 59,999$

7. $\$ 60,000-\$ 69,999$

8. $\$ 70,000-\$ 79,000$

9. $\$ 80,000-\$ 89,000$

10. $\$ 90,000-\$ 99,000$

11. $\$ 100,000$ or greater

12. What is your yearly household income?
1. Less than $\$ 10,000$
2. $\$ 10,000-\$ 19,999$
3. $\$ 20,000-\$ 29,999$
4. $\$ 30,000-\$ 39,000$
5. $\$ 40,000-\$ 49,999$
6. $\$ 50,000-\$ 59,999$
7. $\$ 60,000-\$ 69,999$
8. $\$ 70,000-\$ 79,000$
9. $\$ 80,000-\$ 89,000$
10. $\$ 90,000-\$ 99,000$
11. $\$ 100,000$ or greater

\section{ACKNOWLEDGEMENTS}

Previous versions of this article were presented at the 2009 Midwest and American Political Science Association annual conventions in addition to the 2009 Political Networks Conference at Harvard University. We would like to thank to those who provided us comments at these conferences. We are particularly grateful to Bob Huckfeldt, Lindsey Levitan, and Andrew Bloeser in addition to the Editor and three anonymous reviewers for their insights and valuable suggestions. The authors thank Bilkent University for facilitating the revision stage by offering Elif Erisen a visiting researcher position at the Department of Political Science. We would also like to thank Dennis 
Michel, Syeda Melissa Nuruzzaman, Jennifer Martinek, and Simon Tsui for their excellent research assistance. Correspondence concerning this article should be sent to Elif Erisen, Political Science Department, California Polytechnic State University, 1 Grand Avenue, San Luis Obispo, CA, 93401. E-mail: eerisen@calpoly.edu

\section{REFERENCES}

Barabasi, A. L. (2010). Bursts: The hidden pattern behind everything we do. New York: Dutton Books.

Bassili, J. N., \& Roy, J. P. (1998). On the representation of strong and weak attitudes about policy in memory. Political Psychology, 19, 669-681.

Berelson, B., Lazarsfeld, P. F., \& McPhee, W. N. (1954). Voting: A study of opinion formation in a presidential campaign. Chicago: The University of Chicago Press.

Berinsky, A., \& Kinder, D. (2006). Making sense of issues through media frames: Understanding the Kosovo crisis. Journal of Politics, 68, 640-656.

Brader, T. (2006). Campaigning for hearts and minds: How emotional appeals in political ads work. Chicago: University of Chicago Press.

Brader, T., Valentino, N. A., \& Suhay, E. (2008). What triggers public opposition to immigration? Anxiety, group cues, and immigration threat. American Journal of Political Science, 52, 959-978.

Cacioppo, J. T., \& Petty, R. E. (1981). Social psychological procedures for cognitive response assessment: The thought listing technique. In T. Merluzzi, C. Glass, \& M. Genest (Eds.), Cognitive assessment (pp. 309-342). New York: Guilford Press.

Campbell, A., Converse, P. E., Miller, W. E., \& Stokes, D. E. (1960). The American voter. New York: Wiley.

Cassino, D., \& Erisen, C. (2010). Priming Bush and Iraq in 2008: A survey experiment. American Politics Research, 38, 372-394.

Christakis, N., \& Fowler, J. (2009). Connected: The surprising power of social networks and how they shape our lives. Boston: Little, Brown and Company.

Coser, R. (1975). The complexity of roles as seedbed of individual autonomy. In L. Coser (Ed.), The idea of social structure: Essays in honor of Robert Merton (pp. 85-116). New York: Harcourt Brace Jovanovich.

Damasio, A. R. (1994). Descartes' error: Emotion, reason and the human brain. New York: G. P. Putnam's Sons.

Druckman, J. N., \& Kam, C. D. (2011). Students as experimental participants: A defense of the narrow data base. In J. N. Druckman, D. P. Green, J. H. Kuklinski, \& A. Lupia (Eds.), Cambridge handbook of experimental political science (pp. 70-101). New York: Cambridge University Press.

Erisen, E., \& Erisen, C. (2008). A report on the social network battery in the 2006 ANES pilot study. American National Election Studies, Pilot Study Report, No. nes012063.

Erisen, C., Lodge, M., \& Taber, C. (Forthcoming). Affective contagion in effortful political thinking. Political Psychology.

Faul, F., Erdfelder, E., Buchner, A., \& Lang, A. G. (2009). Statistical power analyses using G*Power 3.1: Tests for correlation and regression analyses. Behavior Research Methods, 41, 1149-1160.

Fishbein, M., \& Ajzen, I. (1975). Belief, attitude, intention, and behavior: An introduction to theory and research. Reading, MA: Addison-Wesley.

Fiske, S. T., \& Taylor, S. E. (1991). Social cognition. New York: McGraw-Hill.

Granovetter, M. S. (1973). The strength of weak ties. The American Journal of Sociology, 78, 1360-1380.

Granovetter, M. S. (1983). The strength of weak ties: A network theory revisited. Sociological Theory, 1, $201-233$.

Green, M. C., Visser, P. S., \& Tetlock, P. E. (2000). Coping with accountability cross-pressures: Low-effort evasive tactics and high-effort quests for complex compromises. Personality and Social Psychology Bulletin, 26, 1380-1391.

Huckfeldt, R. (2001). The social communication of political expertise. American Journal of Political Science, 45, 435-438.

Huckfeldt, R., Beck, P. A., Dalton, R. J., \& Levine, J. (1995). Political environment, cohesive social groups, and the communication of public opinion. American Journal of Political Science, 39, 1025-1054.

Huckfeldt, R., Ikeda, K., \& Pappi, F. U. (2005). Patterns of disagreement in democratic politics: Comparing Germany, Japan, and the US. American Journal of Political Science, 49, 497-514.

Huckfeldt, R., Johnson, P. E., \& Sprague, J. (2004). Political disagreement: The survival of diverse opinions within communication networks. New York: Cambridge University Press.

Huckfeldt, R., \& Mendez, J. M. (2008). Moths, flames, and political engagement: Managing disagreement within communication networks. Journal of Politics, 70, 83-96.

Huckfeldt, R., \& Sprague, J. (1984). Networks in context: The social flow of political information. American Political Science Review, 81, 1197-1216. 
Huckfeldt, R., \& Sprague, J. (1995). Citizens, politics, and social communication. New York: Cambridge University Press.

Jost, J. T., Glaser, J., Kruglanski, A. W., \& Sulloway, F. J. (2003). Political conservatism as motivated social cognition. Psychological Bulletin, 129, 339-375.

Kahneman, D., Slovic, P., \& Tversky, A. (1982). Judgment under uncertainty: Heuristics and biases. New York: Cambridge University Press.

Kahneman, D., \& Tversky, A. (1981). The framing of decisions and the psychology of choice. Science, 211, 453458.

Krosnick, J. A., \& Petty, R. E. (1995). Attitude strength: An overview. In R. E. Petty \& J. A. Krosnick (Eds.), Attitude strength: Antecedents and consequences (pp. 1-24). Hillsdale, NJ: Lawrence Erlbaum.

Kunda, Z. (1987). Motivated inference: Self-serving generation and evaluation of causal theories. Journal of Personality and Social Psychology, 53, 636-647.

Kunda, Z. (1990). The case for motivated reasoning. Psychological Bulletin, 108, 480-493.

Lane, R. (1969). Political thinking and consciousness: The private life of the political mind. Chicago: Markham Publishers.

Lau, R., \& Redlawsk, D. (2001). Advantages and disadvantages of cognitive heuristics in political decision making. American Journal of Political Science, 45, 951-971.

Lazer, D., Pentland, A., Adamic, L., Aral, S., Barabasi, A-L., Brewer, D., Christakis, N., Contractor, N., Fowler, J., Gutmann, M., Jebara, T., King, G., Macy, M., Roy, D., \& Alstyne, M. V. (2009). Computational social science. Science, 323, 721-723.

Lebo, M., \& Cassino, D. (2007). The aggregated consequences of motivated reasoning and the dynamics of partisan presidential approval. Political Psychology, 28, 719-746.

Levitan, L., \& Visser, P. (2008). The impact of social context on resistance to persuasion: Effortful versus effortless responses to counter-attitudinal information. Journal of Experimental Social Psychology, 44, 640-649.

Levitan, L., \& Visser, P. (2009). Social network composition and attitude strength: Exploring the dynamics within newly formed social networks. Journal of Experimental Social Psychology, 45, 1057-1067.

Lodge, M., \& Taber, C. (2000). Three steps toward a theory of motivated political reasoning. In A. Lupia, M. D. McCubbins, \& S. L. Popkin (Eds.), Elements of reason: Understanding and expanding the limits of political rationality (pp. 183-213). New York: Cambridge University Press.

Lodge, M., \& Taber, C. (2005). The automaticity of affect for political leaders, groups, and issues: An experimental test of the hot cognition hypothesis. Political Psychology, 26, 455-482.

Marcus, G. E. (1988). The structure of emotional response: 1984 presidential candidates. American Political Science Review, 82, 737-761.

Marcus, G. E. (2003). The psychology of emotion and politics. In D. O. Sears, L. Huddy, \& R. Jervis (Eds.), Oxford handbook of political psychology (pp. 182-221). Oxford: Oxford University Press.

Marcus, G. E., Neumann, R., \& MacKuen, M. B. (2000). Affective intelligence and political judgment. Chicago: University of Chicago Press.

McClurg, S. D. (2006). Political disagreement in context: The conditional effect of neighborhood context, discussion, and disagreement on electoral participation, Political Behavior, 28, 349-366.

McGuire, W. J., \& McGuire, C. V. (1991). The content, structure, and operation of thought systems. In R. S. Wyer, Jr. \& T. K. Srull (Eds.), Advances in social cognition, volume IV (pp. 1-79). Hillsdale, NJ: Lawrence Erlbaum.

Mintz, A., Redd, S. B., \& Vedlitz, A. (2006). Can we generalize from student experiments to the real world in political science, military affairs, and international relations? Journal of Conflict Resolution, 50, 757-776.

Mutz, D. (2002a). Cross-cutting social networks: Testing democratic theory in practice. American Political Science Review, 96, 111-126.

Mutz, D. (2002b). The consequences of cross-cutting networks for political participation. American Journal of Political Science, 46, 838-855.

Mutz, D. (2006). Hearing the other side: Deliberative versus participatory democracy. New York: Cambridge University Press.

Nisbett, R. E., \& Ross, L. (1980). Human inference: Strategies and shortcoming of social judgment. Englewood Cliffs, NJ: Prentice-Hall.

Page, B. I., \& Shapiro, R. Y. (1992). The rational public: Fifty years of trends in Americans' policy preferences. Chicago: University of Chicago Press.

Pennington, N., \& Hastie, R. (1992). Explaining the evidence: Tests of the story model for juror decision making. Journal of Personality and Social Psychology, 62, 189-206.

Pennington, N., \& Hastie, R. (1993). Reasoning in explanation-based decision-making. Cognition, 49, $123-163$. 
Popkin, S. (1991). The reasoning voter: Communication and persuasion in presidential campaigns. Chicago: University of Chicago Press.

Redlawsk, D. (2002). Hot cognition or cool consideration? Testing the effects of motivated reasoning on political decision. Journal of Politics, 64, 1021-1044.

Redlawsk, D. (2006). Feeling politics: Emotion in political information processing. New York: Palgrave Macmillan.

Redlawsk, D., Civettini, A., \& Lau, R. (2007). Affective intelligence and voting: Information processing and learning in a campaign. In W. R. Neuman, G. E. Marcus, M. MacKuen, \& A. N. Crigler (Eds.), Affect effect: The dynamics of emotion in political thinking and behavior (pp. 152-179). Chicago: University of Chicago Press.

Rosenberg, W. (2002). The not so common sense: Differences in how people judge social and political life. New Haven, CT: Yale University Press.

Simon, H. A. (1957). Models of man: Social and rational; mathematical essays on rational human behavior in society setting. New York: Wiley.

Sniderman, P. M., Brody, R. A., \& Tetlock, P. E. (1991). Reasoning and choice: Explorations in political psychology. New York: Cambridge University Press.

Taber, C., \& Lodge, M. (2006). Motivated skepticism in the evaluation of political beliefs. American Journal of Political Science, 50, 755-769.

Tetlock, P. E. (1983). Cognitive style and political ideology. Journal of Personality and Social Psychology, 45, 118-126.

Tetlock, P. (1984). Cognitive style and political belief systems in the British House of Commons. Journal of Personality and Social Psychology, 46, 365-375.

Tetlock, P. (1985). Integrative complexity of American and Soviet foreign policy rhetoric: A time-series analysis. Journal of Personality and Social Psychology, 49, 1565-1585.

Tomz, M., Wittenberg, R., \& King, G. (2003). CLARIFY: Software for interpreting and presenting statistical results. Journal of Statistical Software, 8, 1-30.

Visser, P. S., \& Mirabile, R. R. (2004). Attitudes in the social context: The impact of social network composition on individual-level attitude strength. Journal of Personality and Social Psychology, 87, 779-795.

Wegener, D. T., Downing, J., Krosnick, J. A., \& Petty, R. E. (1995). Measures and manipulations of strength-related properties of attitudes: Current practice and future directions. In R. E. Petty \& J. A. Krosnick (Eds.), Attitude strength: Antecedents and consequences (pp. 1-24). Hillsdale, NJ: Lawrence Erlbaum.

Zaller, J. R., \& Feldman, S. (1992). A simple theory of the survey response: Answering questions versus revealing preferences. American Journal of Political Science, 36, 579-616. 